\title{
Chloracne from the accidental production of tetrachlorodibenzodioxin
}

\author{
GEORGE MAY ${ }^{1}$ \\ General Practice, Bolsover, Derbyshire and Coalite and Chemical Products Limited
}

\begin{abstract}
May, G. (1973). British Journal of Industrial Medicine, 30, 276-283. Chloracne from the accidental production of tetrachlorodibenzodioxin. Following the accidental production of 2,3,7,8-tetrachlorodibenzodioxin (dioxin) as the result of an exothermic reaction at a chemical plant in Derbyshire, 79 cases of chloracne were recorded, many of them severe. Contrary to the usual experience they have responded very favourably to treatment and there were no cases of contact chloracne among relatives or domestic animals in the initial outbreak. However, two cases of contact chloracne were recorded three years later.

Similar incidents are known to have occurred in both Europe and the United States of America, almost invariably accompanied by widespread severe illness and with fatalities. Apart from one death due to an explosion which followed the exothermic reaction the more serious sequelae, which may range from depression and loss of weight to liver, kidney, and cardiac failure as well as malignant disease, have not occurred.

A quick and reliable method of biological assay for the presence of dioxin in produced trichlorophenol was developed based on oral dosage to rabbits with assessment of liver function at fixed time intervals thereafter. This test has already been superseded by instantaneous gas-liquid chromatography.

An entirely new plant with suitable modifications and multiple safety features has now been in satisfactory operation for three years.
\end{abstract}

Production of 2,4,5-trichlorophenol (2,4,5-TCP) began in August 1965 at Bolsover, Derbyshire at the Fine Chemicals Unit of Coalite and Chemical Products Limited.

$1,2,4,5,-$ Tetrachlorobenzene and ethylene glycol were charged to the reactor together with ortho dichlorobenzene and $100^{\circ} \mathrm{Tw}$ caustic soda solution (Fig. 1).

The vessel was heated by oil and reaction took place at about $180^{\circ} \mathrm{C}$ with an arbitrary upper limit of $200^{\circ} \mathrm{C}$. The progress of the reaction was monitored by sampling, and on completion the vessel contents were cooled to $140^{\circ} \mathrm{C}$. Steam was then injected into the reaction vessel in order to recover the ortho dichlorobenzene which was used purely as a solvent to prevent blocking of the condenser by solid

${ }^{1}$ Requests for reprints to Dr. G. May, 1a Welbeck Road, Bolsover, nr. Chesterfield. tetrachlorobenzene. After the ortho dichlorobenzene ceased to be evolved, the reaction mixture was run into water in the separator. The contents of the separator were acidified with concentrated sulphuric acid at a temperature of about 70 to $80^{\circ} \mathrm{C}$. After the separation of the organic layer containing 2,4,5-TCP from the aqueous phase, agitation was continued for a further 15 minutes and the contents of the vessel were allowed to stand for two hours. The aqueous phase was then syphoned off and transferred to a storage vessel, and a second waterwash was added to the organic layer. A third wash was also required, and finally a wash of town water was run to the effluent treatment drain. Since about 1966-67 caustic soda flake has been charged directly to the reactor and no water has been added at this stage.

The aqueous phase consisting of the washings, which contained sodium chloride, ethylene glycol, and digol was distilled under vacuum to remove 


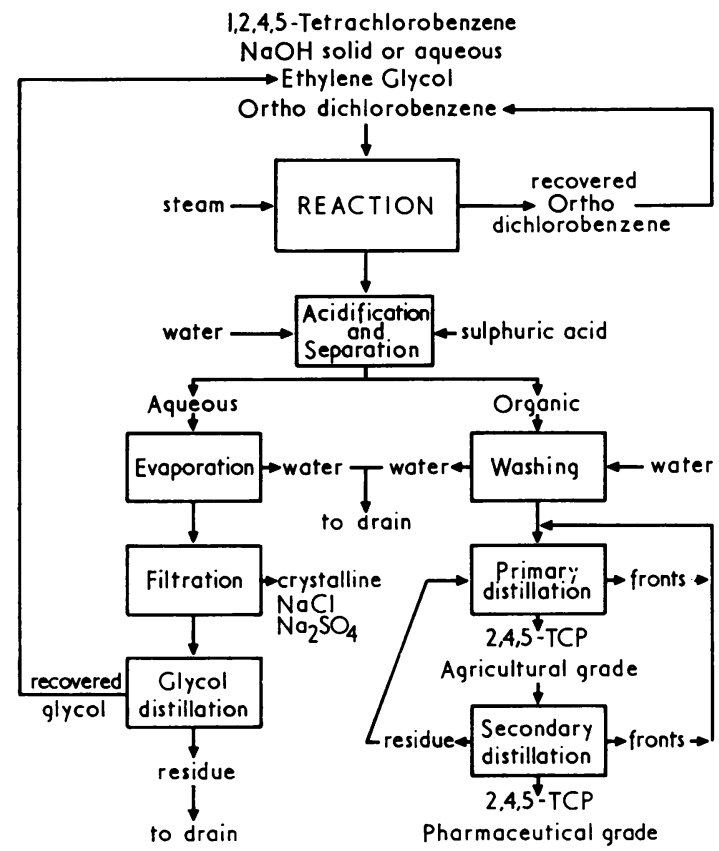

FIG. 1. Schematic representation of the reaction in 2,4,5-trichlorophenol production.

water. When the base temperature of the still reached $120^{\circ} \mathrm{C}$ distillation was discontinued and the still contents were transferred to a centrifuge where the precipitated salts were removed by filtration. The liquor remaining after filtration, which consists essentially of ethylene glycol, was fractionated and the glycol thus recovered was recycled to the first stage of the process.

\section{Distillation}

The organic material which was separated off was distilled at a vacuum of $20 \mathrm{~mm}$ of mercury. The residues from the still were run to waste, the fronts were recycled to the organic layer from the washing process, and the main fraction produced was agricultural grade 2,4,5-TCP. In the Coalite process a proportion of the pure or pharmaceutical grade of 2,4,5-TCP was produced by a further fractionation of the agricultural grade. The residues from this second distillation were fed back into the primary distillation and the fronts were added to the agricultural grade material for sale. The main distillation was the pharmaceutical grade material.

The agricultural grade was reacted with monochloroacetic acid to give 2,4,5-trichlorophenoxyacetic acid $(2,4,5-\mathrm{T})$ and the pharmaceutical grade was condensed with formaldehyde to form hexachlorophane.
Production had been maintained for three years on the above basis. If the arbitrary temperature deadline was reached the process was cooled by lowering the temperature of the heating oil. This regulation was manually controlled.

\section{Uses of finished products}

The most important application of 2,4,5-T is for killing woody plants, several species of which have been shown to be more susceptible to 2,4,5-T than to 2-methyl, 4-chlorophenoxyacetic acid (MCPA) or 2,4-dichlorophenoxyacetic acid (2,4-D). Both amine and ester derivatives are available commercially, the latter being the most important. The esters are applied either in emulsions for overall foliage sprays or in solution in a mineral oil such as vaporizing oil or diesel oil for local application to frill girdles, or to stumps, or by the 'basal bark' technique. Commercial products often contain a mixture of 2,4-D and 2,4,5-T esters for reasons of economy and the greater range of effectiveness on different plant species gained by including the two chemicals.

Like the other auxin type herbicides, 2,4,5-T is of low mammalian toxicity. It is generally less effective on herbaceous species than MCPA and 2,4-D but it is much more persistent in the soil.

Hexachlorophane has for many years been used as a bacteriostatic agent in operating theatres and it is most likely that this use will continue. It is also used in topical applications in dermabrasion, and in a large range of toilet preparations ranging from soap to vaginal sprays and baby powders. Recently some baby powders have contained hexachlorophane in a concentration of $6 \%$ instead of the recommended maximum of $0.6 \%$, and its use in toilet preparations is under review.

\section{Incident}

At midnight on 23 April 1968, the reaction temperature reached $175^{\circ} \mathrm{C}$ and thereafter it rose continuously for 50 minutes. When it had reached a point somewhere in excess of $250^{\circ} \mathrm{C}$ an explosion of considerable violence occurred and the supervising chemist was killed by falling masonry. Subsequent analysis indicates that the explosion was of a double nature. When the temperature had reached $225^{\circ} \mathrm{C}$ the process began to generate its own heat and the initial rupturing of the vessel was due to the advance of this exothermic reaction. Ethylene glycol and orthodichlorobenzene vapours were released in quantity into the atmosphere. In the presence of atmospheric oxygen these constituted an explosive mixture which appears to have been detonated by an overhead electric lamp. Extensive local damage was done to both plant and building and a con- 
siderable part of the wall in the proximity of the explosion was demolished. By far the greater part of all four floors, however, had apparently been completely unaffected by blast or residue.

The entire Fine Chemicals Unit was closed down pending clinical and laboratory investigation on 14 employees who were in the building at the time of the incident or who had had to enter in its aftermath.

\section{Clinical and laboratory findings}

Two men complained of tiredness, and three of slight tightness of the chest, but clinical examination revealed nothing of note. The investigations included liver function tests, full blood counts, and urinalysis.

Two men, the works engineer and a senior laboratory technician, both of whom had been closely associated with process development and with continuing pilot plant research, did not enter the building until some hours after the explosion. These two men were the most likely to show any work-induced condition which preexisted the explosion but neither of them had any abnormality.

Of the remaining 12 men, only one showed no abnormality in any test. Three men showed one abnormality, four showed two, and another four showed three abnormalities. Among these were 13 abnormal liver function tests: $\mathrm{ZnSO}_{4}$ turbidity in six men, thymol turbidity in two men, and serum transaminase in five men were abnormally high (Table). One man had albuminuria and one had an abnormal serum protein level. White cell counts in five men were regarded by the haematologist as being somewhat too high or too low and there were three men with glycosuria.

These findings persuaded us to treat the incident with extreme caution and to wait and see whether the changes were progressive. Fortunately, all the men reported fit very shortly after, and 10 days later practically all the tests were within normal limits. One man with $1 \%$ glycosuria was known to have had this before the explosion.

In view of these satisfactory findings the building was re-opened. All damaged and obviously dirty areas were sealed off to be decontaminated properly and at leisure, while the remainder of the building was subjected to a thorough spring clean. Production was then resumed in the greater part of the plant.
For a time work continued normally. Process operators were watched particularly carefully but they all remained well. However, certain men, all of whom had been in the Fine Chemicals Unit, developed a mild but peculiar skin condition. This consisted of a slight malar erythema and the eruption of tiny vesicles around the borders of the pinnae (Fig. 2). Occasionally there was evidence of mild

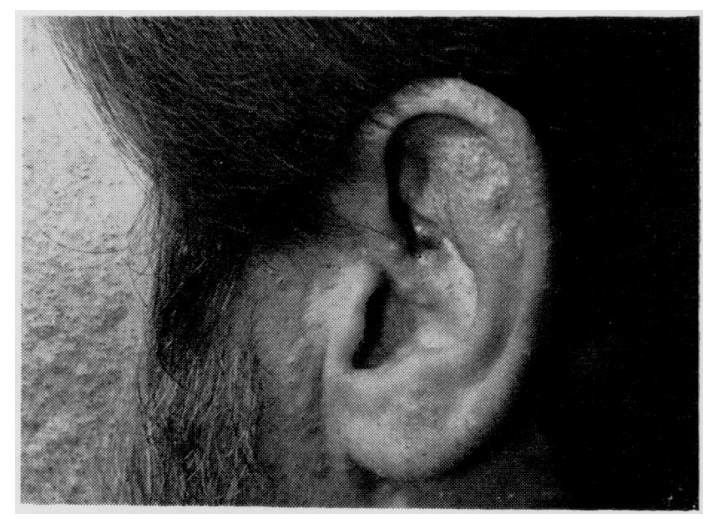

FIG. 2. Typical established chloracne of pinna showing cysts and comedones.

conjunctivitis. These men were not continuously occupied in the same building as operators who always wore gloves, but were mostly fitters, plumbers, and electricians who only entered the unit on occasion to do specified jobs with bare hands. Obviously, therefore, it was something which had been deposited or embedded in the matrix of the building itself which was causing the reaction and which was being absorbed by contact. The diagnosis quickly established itself as chloracne and it became widespread. Later it was established that the toxic material was 2,3,7,8-tetrachlorodibenzodioxin (dioxin) (Fig. 3), a reaction product of the sodium salt of trichlorophenol (Milnes, 1971).

From 8 May to 8 December 1968, 79 cases of chloracne were recorded. Not all individuals presented with malar erythema, etc., but those who did generally became severe and extensive cases. Some men appeared

TABLE

Liver Function Tests in 14 Men in Building at Time of Explosion or who entered it SOON AFTERWARDS

\begin{tabular}{|c|c|c|c|c|c|c|c|c|c|c|c|c|c|c|c|c|}
\hline & & & \multicolumn{14}{|c|}{ Patient } \\
\hline & & & $l$ & 2 & 3 & 4 & 5 & 6 & 7 & 8 & 9 & 10 & 11 & 12 & 13 & 14 \\
\hline $\begin{array}{l}\text { Thymol turbidity . } \\
\text { (normal upper limit } 2.5 \text { units) }\end{array}$ & . & .. & $1 \cdot 2$ & 0.7 & 0.5 & 0.7 & 0.5 & $1 \cdot 2$ & 0.8 & 0.6 & 1.8 & $1 \cdot 1$ & $1 \cdot 2$ & $2 \cdot 5$ & $3 \cdot 8$ & 3.05 \\
\hline $\begin{array}{l}\text { Zinc turbidity } \\
\text { (normal upper limit } 10 \text { units) }\end{array}$ & . & . & 7 & 8 & 17 & 8 & $13 \cdot 5$ & $12 \cdot 8$ & 9.9 & $12 \cdot 7$ & $7 \cdot 5$ & $13 \cdot 5$ & 5 & $12 \cdot 5$ & $5 \cdot 5$ & $9 \cdot 4$ \\
\hline $\begin{array}{l}\text { SGPT } \\
\text { (normal upper limit } 35 \text { units) }\end{array}$ & . & . & 18 & 20 & 32 & 16 & 18 & 36 & 42 & 22 & 40 & 6 & 28 & 40 & 6 & 36 \\
\hline
\end{tabular}




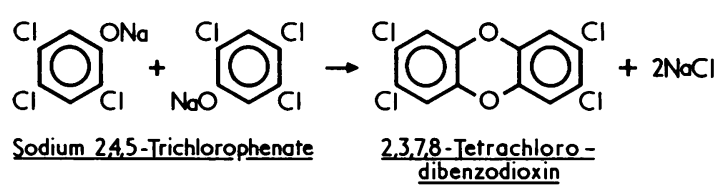

FIG. 3. Formation of one molecule of 2,3,7,8-tetrachlorodibenzodioxin from two molecules of sodium 2,4,5-trichlorophenol. (This is the International Union of Pure and Applied Chemistry nomenclature; in some earlier literature the compound has been referred to as 2,3,6,7-tetrachlorodibenzodioxin.)

to react within days while others did not present with established symptoms until between two and three months after the last known exposure. Younger men, particularly those with fair complexions, were first affected, while the reaction was most persistent in sallow-skinned men in the $25-40$ age group, particularly if their personal hygiene was neglected.

The established clinical condition was present on the face in all cases. Inclusion type cysts, ranging from 1 to $7 \mathrm{~mm}$ in diameter, were diagnostic (Fig. 4). The malar

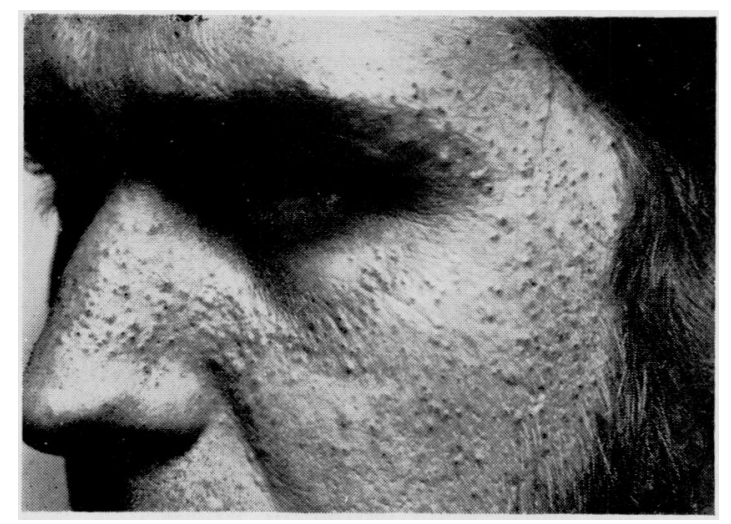

FIG. 4. Facial chloracne of the multiple comedone and small cystic type showing well the most common distribution.

areas were worst affected, the cysts diminishing in number as the condition extended on to the cheeks, maxillary areas, and sides of the neck. The ear lobes, post-auricular triangles, and suboccipital hair-line were also involved. In some men the condition was predominantly cystic, while in others there was a liberal smattering of comedones, even to the extent that not a pore had been missed and the whole side of the face bore a dusky grey hue. The facial condition varied from very mild and just diagnosable to severe and obvious.

The other parts of the body most often involved were the extensor aspects of the arms, the lateral aspects of thighs and calves, the back, and the sternum in that order. In five cases the antecubital fossae were involved (Fig. 5),

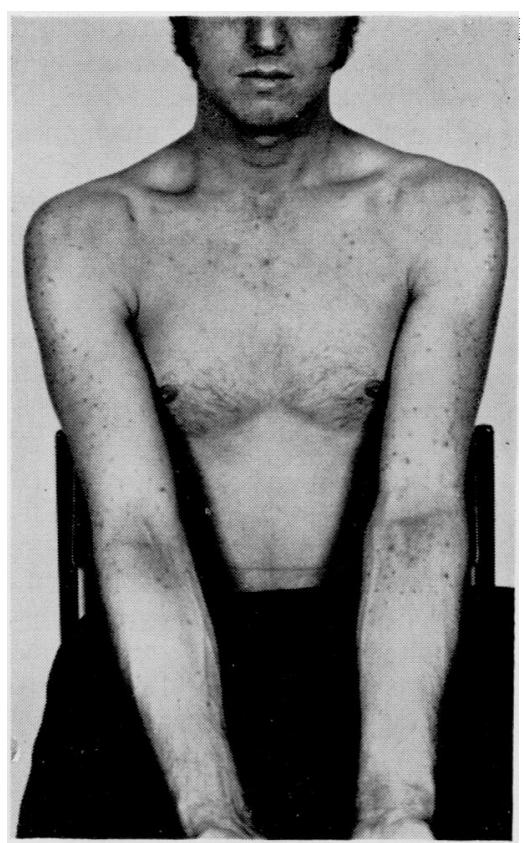

FIG. 5. Chloracne affecting the antecubital fossae.

a condition which has not previously been described, and in two cases the medial aspects of the thighs were affected.

Postular folliculitis, presumably from secondary infection, was present in a moderate number of cases.

\section{Treatment}

In the early stages it was found that the use of ointments, creams, pastes, and steroids tended to aggravate the condition. Oral oxytetracycline, $250 \mathrm{mg}$, two to four times daily, was used for pustular follicles, depending on the severity and extent of the infection. Otherwise, in the more severe cases a $1 \%$ solution of cetrimide was applied after the daily bath; in moderately severe cases zinc sulphide lotion, BPC, was used while mild cases were given no local medication whatever. Oxytetracycline and cetrimide were often used together. Severe to moderate cases were also treated with ultraviolet light at the works. Treatment was reinforced by the most rigorous campaign of works and personal cleanliness. A system for laundering overalls was introduced and the men were advised to use the showers regularly, and to keep the garments they wore under their overalls clean. They were also asked to change into clean clothing before leaving the works. Hair oils were discouraged and thorough rinsing of the skin after washing, particularly shaving, was recommended. Finger nails were kept short and clean and steaming of the face 
at home, followed by gentle squeezing of comedones and cysts with subsequent application of eau-decologne or astringent lotion, was advised. The men were also recommended to get as much sunshine as possible.

Within the next four to six months the great majority of cases made an almost complete recovery, in reverse order, with the younger fairer individuals leading. Ten men who had shown disappointing progress under the general regime were given intensive steam bathing followed by ultraviolet radiation, after which even their chloracne began to resolve.

\section{Treatment of the building}

The Fine Chemicals Unit was again closed and no one was allowed into it without special protective clothing, including full face mask, gloves, and boots. Anyone coming out of the building had to do so through a special decontamination room where he had assistance to change. The presence of dioxin on the walls, roof, and other parts of the plant was shown by painting a solution prepared from rubbings taken from different parts of the building on the inner side of rabbits' ears, as first demonstrated by Adams, Irish, Spencer, and Rowe (1941). The results were so consistent that they were checked by testing the plain solvent and even rubbings from new asbestos to demonstrate that these, on their own, could not produce chloracne. As the rabbit's ear test took eight weeks a method of oral dosage and control was developed with estimation of the serum alanine aminotransferase at fixed time intervals. Not only was this method faster but it was more reproducible and reliable.

It was obvious that the entire building would have to be thoroughly cleaned and resurfaced. Heavy and expensive equipment which had been affected by blast or was heavily contaminated was buried 150 feet (45 metres) deep at the base of an open-cast coal mine. Dioxin is water insoluble and will not be leached out.

After the most extensive and vigorous decontamination, swabs from the areas previously contaminated were tested on rabbits and all were found to be negative. Rabbits were also exposed to the atmosphere of the building itself for one week with negative results. Production began once more and since then no new case of chloracne has developed in that building, nor has chloracne appeared among the decontamination squad.

\section{Discussion}

Manufacturing procedure at Coalite did not utilize either pressure or agitation in the autoclave stage. Explosions elsewhere, of which the research staff were aware, used both but at a lower operating temperature. It was believed that the Coalite method could not produce an explosion and, furthermore, in the event of an unforeseen temperature rise, that there would be fewer and less dangerous toxic byproducts. As far as is known, the Coalite method was unique in that it used glycol (boiling point $197^{\circ} \mathrm{C}$ ) while other methods utilized methanol (boiling point $64^{\circ} \mathrm{C}$ ). Owing to the lower boiling point of the latter, high pressures were required before a suitable reaction temperature could be reached in the liquid phase. The Coalite reaction took place at little more than atmospheric pressure. Attempts to produce explosions in grossly overheated pilot plants had failed and it was not until after the incident that the more toxic byproducts were isolated in such pilot plants. Neither has it since been possible to reproduce an explosion.

The only available reference to dangerous byproducts from the interaction of similar chemicals at explosive temperature and force (Quarterly Safety Summary of the Association of British Chemical Manufacturers, 1960) briefly described two incidents. In the first, a charged autoclave was heating up when the pressure and temperature increased rapidly and an explosion ensued, resulting in fatal injuries. In the second incident, which occurred in a similar process, the temperature rose unexpectedly to $400^{\circ} \mathrm{C}$ with escape of vapours. After 10 days all 50 persons exposed fell ill and had more or less severe liver damage. It was thought that spontaneous decomposition had taken place and that pentachlorooxydiphenyloxide was formed. The residues were very toxic, very sticky, and difficult to clean up.

When a plant in Germany was told the reason for the cessation of their supplies of another chemical, normally produced in the Fine Chemicals Unit, they provided detailed information about a similar experience some years earlier in which they had identified dioxin as the toxic material. Dioxin is a natural, very minor contaminant in the routine manufacture of trichlorophenol. It does not appear to any great extent unless the reaction temperature exceeds $200^{\circ} \mathrm{C}$ and it is normally removed in the purification process. Thereafter it becomes an increasing constituent of the reaction products. In the German incident there had been some months of chronic overheating during which all the workers and many of their wives, children, and domestic animals had developed chloracne. It was only after production was finally terminated by an explosion that the gravity of the situation was fully realized and intensive research was carried out to isolate the toxin.

Exact figures of individuals involved or of morbidity or mortality rates were not given, but there were a number of cases of severe liver disorder, some 
of them fatal. Fifteen years later one individual was expected to die soon from this and others were still under treatment. One death from pulmonary carcinoma had been rejected as being attributable while one of intestinal sarcoma had been accepted. The works medical officer considered that dioxin passed into the system by inhalation as well as orally and transdermally. He was indeed surprised that our chloracne cases had developed no other symptoms.

The German literature on the subject of dioxin and its toxicity makes no specific reference to this particular plant. There can be little doubt, however, that this incident along with two others forms the basis of a series of articles (Kimmig and Schulz, 1957; Bauer, Schulz, and Spiegelberg, 1961; and Schulz, 1968) which describe in great detail not only chloracne but all the toxic reactions attributed to dioxin, which include liver damage, emphysema, myocardial degeneration, raised blood pressure, renal damage, reflex irregularities, depression, disturbances of memory and concentration, etc. Oettal (Hofmann, 1957) reported liver necrosis in rabbits kept in cages adjacent to those exposed to dioxin. Furthermore, unexposed animals which were put into cages previously occupied by exposed animals also suffered liver necrosis so that a virus infection was at first suspected.

Crow (1970) defined chloracne as the 'production in the human subject of a type of acne with characteristic clinical features, so far produced only by aromatic chlorinated hydrocarbons of varying structures'. It is quite distinct from all the other acnes of external origin.

The unchlorinated dioxin molecule does not cause acne and is also non-toxic. It has been argued that the toxicity is related to the degree of chlorination. This is demonstrably untrue because the $2,3,7,8-$ tetrachlorinated dioxin has often been shown to be not only the most toxic but also the most powerful cause of acne. The interrelationship or positioning of chlorine atoms in dioxin molecular space is, therefore, of paramount importance. As in the dioxins, some members of the chlornaphthalenes and the diphenyloxides cause chloracne. There is a strong school of thought which believes that it is not only the position of the chlorine atoms in molecular space but their symmetry which is responsible for their biological activity. Whether it be one or both, we have a whole series of compounds whose unchlorinated molecules are inert but which, when chlorinated, and depending on the number and position of their chlorine atoms, cause an identical clinical condition. They have, therefore, a common factor and I suggest that this should be called the chloracne factor'.

The literature shows that chloracne is extremely resistant to all forms of treatment. We saw cases in Germany which were still active after 15 years' treatment and freedom from contact. At the present time, four years after the incident at Bolsover, chloracne is just diagnosable in seven cases. At no time did we have to resort to the incision of cysts, neither has there been any legacy of severe scarring. Whether this is due to the comparatively short period of exposure to dioxin, to the comprehensive personal and environmental hygiene measures or to a mixture of both, is difficult to say.

Though chloracne was the presenting symptom, the possibility of underlying serious disease was not ignored. No other ailment presented which could reasonably have been held attributable to dioxin exposure and continuous monitoring of liver function tests and urinalysis was satisfactory.

The German company had indicated that the bromsulphthalein test of liver function and serum gamma-globulin levels were also important. These were checked in some of the more severe cases without revealing any abnormality. Their recommendation that we should carry out a few liver biopsies was discarded, for the time being at any rate, owing to the continued fitness of the men, the normality of the other investigations, and our desire not to create undue alarm. Time appears to have proved this decision to be correct. During the months that followed no contact, such as wife, child or domestic pet, was reported to have chloracne.

Rabbits were used to demonstrate the presence of dioxin as Hofmann and Neumann (1952), dealing with a similar incident, had indicated that rats introduced to the autoclave room had shown no reaction and guinea-pigs only non-specific reactions. Cats, however, suffered diffuse loss of hair after a lengthy latent period, while rabbits died of acute liver necrosis after a latent period of one to three weeks. Obviously, rabbits are extremely sensitive to dioxin as a liver intoxicant.

When the German company had resumed its own production in the early 1950 s they had not thereafter released a single batch of trichlorophenol without submitting a sample to an eight-week biological assay against the rabbit's ear. If chloracne was then produced the dioxin content was too high.

Trichlorophenol is very important commercially and it was therefore necessary to carry out toxicity tests on Coalite's own commercial product before going into production once more. A great deal of information was available on animal exposure (Anderson, Arndt, Goldbey, and Jones, 1949; Farquharson, Gage, and Northover, 1958; McCollister, Lockwood, and Rowe, 1961) which indicated that trichlorophenol was not toxic unless given in massive dosage. Indeed, McCollister et al. (1961) had shown that the rabbit, though not as resistant as the rat, did have a high tolerance to trichlorophenol. It was shown that a dose of the 
Coalite commercial product of about $1 \mathrm{~g} / \mathrm{kg}$ had to be given before it was lethal.

In the incident described here, the chlorine atoms in dioxin were situated at points $2,3,7$, and 8 , which appears to be the most toxic of the dioxin group. There are, however, eight points onto which a chlorine atom can be hooked and therefore there can be over 60 different chlorinated dioxins, depending on the number and position of the chlorine atoms. Very little is known about the other chlorinated dioxins in which the biological activity is also dictated by the number and position of the chlorine atoms.

Although Coalite chemists failed to produce an explosion experimentally using the old process, one did take place eventually in the production plant, despite the absence of pressure and agitation. Whether the sheer size of the commercial plant could excite an exothermic reaction into becoming explosive or whether there was any other constituent is not possible to say. An exotherm has been apparent experimentally at $400^{\circ} \mathrm{C}$, and dioxin has been recovered and purified from this production (Milnes, 1971).

An entirely new plant to produce 2,4,5-trichlorophenol in which all processes, including temperature control and other new techniques, are automated has been in operation for three years without the occurrence of chloracne or production of dioxin. All batches are now submitted to gas liquid chromatographic (GLC) analysis by a technique specially developed to test for dioxin and which is sensitive to $\mathbf{0 . 2}$ p.p.m. This level is considered to be well within the limits of acceptability.

In the process for trichlorophenol production currently in use orthodichlorobenzine has been replaced by petroleum ether. The former process involved a total condenser and external separator (glass condenser). The petrol ether process incorporates a reflex condenser fabricated from steel and reflex divider which is much simpler and safer. Additionally, each reactor has five fail-safe functions built into the instrumentation independent of the programme control. These functions are designed to shut down a reactor automatically in the event of a fail-safe condition being reached and to shut down that reactor in such a way that an exothermic reaction is not possible. The programming computers memorize the slightest deviation towards a fail-safe situation and are therefore continuously updated. The temperature of the reaction is held at $180^{\circ} \mathrm{C}$ until tests show that there is no dioxin in the reaction mixture.

A fine powder such as purified dioxin could obviously be absorbed by inhalation and oral ingestion. In our own case, the contaminant was trapped in a heavy greasy deposit so we are inclined to rule out inhalation completely. Early liver function tests appeared to indicate the presence of a toxin which might have been inhaled but these departures from normal were transient and none of the individuals concerned developed chloracne. In the event the workers who did develop chloracne were those who had to get down to handling pipes, joints, cables, and the like with their bare hands, and this suggests that these men absorbed the dioxin through the skin. In our opinion, there must then be some excretion of absorbed dioxin or its products by the facial pores. It is suggested that in these light-exposed areas, such as pinnae and malar region, a chemical reaction takes place, probably itself light-induced, causing oedema and obstruction of the follicles with subsequent formation of retention cysts and comedones. It is not until the follicles re-open and function normally that chloracne begins to clear, and it is fully accepted that the methods by which this becomes possible were not, in our case at least, those necessarily applicable to ordinary acne. At the Coalite Refinery approximately 500 men are employed and no new case of chloracne has appeared among them since December 1968.

In March 1971, construction began of an entirely new building for an unrelated product using, almost throughout, factory fresh materials. This building was erected by outside contractors using their own employees. After only three weeks at this work two of these employees developed a skin condition which they reported to their own doctors and thereafter to separate dermatologists. The son of one (Fig. 6) and the wife of the other also developed this condition which was undoubtedly chloracne (Jensen and Walker, 1972). The only piece of equipment with which they had any authority to come in contact, which could possibly have been contaminated with dioxin, was a large metal vessel which had been subject to the most rigorous cleaning. Coalite's own employees had not only welded new collars to it after burning new vents but had actually been inside it. Later tests (GLC and double biological assay) on this vessel failed to reveal the presence of dioxin. The only contact these individuals had was when they connected up new equipment to the new collars. Furthermore, they only worked together for a day or two and yet they developed the most persistent chloracne of all; it is believed they are still undergoing intensive treatment, and they were the only people to pass the condition on at home. We have been unable to satisfy ourselves where or how this contamination occurred. Coalite's own workers must have been at very much greater risk over many months before. Even if it could be postulated that tolerance can develop to dioxin, which is not so, examples should have been seen in newcomers to the Company staff. It is certainly the case that the men affected did not avail themselves of the high-grade personal hygiene facilities at the 


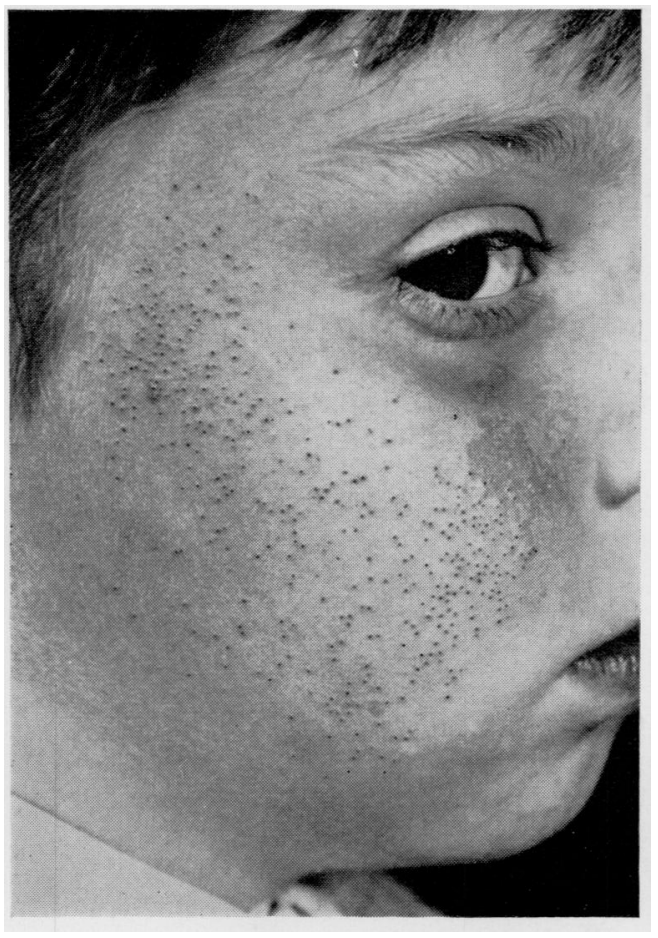

FIG. 6. Case of contact chloracne showing fairly typical comedone distribution but no cysts. There is some malar pigmentation, a condition frequently described elsewhere but one which did not develop among the original cases.

works for either their persons or their clothing and this may explain the home transference. The wife developed symptoms nine months after her husband, and eight months after his last employment here. It was not possible to demonstrate dioxin by GLC in the contents of his facial cysts, something which had not been tried on the original cases.

Recently, environmentalists have been watching dioxin contamination of $2,4,5-\mathrm{T}$ very carefully. Many of the early batches of this herbicide had been produced at excessive temperatures and, on release, contained up to 40 or even 60 p.p.m. of dioxin. Regulations, quality control, and cessation of production by companies without adequate technical knowledge have now eliminated dioxin contamination. The United States Agricultural Research Service (Cherry, 1972) has analysed samples from Florida experimental plots that had received for eight years massive 2,4,5-T sprays with dioxin traces up to 40 p.p.m. without finding residues. Dioxin residues have not been found at the lower limit of detection ( 0.05 p.p.m.) in tissues of the bald eagle collected in 15 widely separated states.
I wish to thank the Directors of Coalite and Chemical Products Limited for permission to publish this article, the Coalite Research Laboratory, where pure dioxide was isolated, the late Dr. Herbert Bondy, chemical adviser, and Dr. Ken Payne, research director, for comments on the technical aspects of the paper, and The Huntingdon Research Institute where extensive animal investigations were carried out, largely by Ronald E. Davies. Dr. Doris Fletcher, formerly consultant dermatologist at Chesterfield Royal Hospital, advised on the treatment of the patients.

\section{References}

Adams, E. M., Irish, D. D., Spencer, H C., and Rowe, V. K. (1941). The response of rabbit skin to compounds reported to have caused acneform dermatitis. Industrial Medicine, Industrial Hygiene Section, 2, 1-4.

Anderson, G. W., Arndt, C. H., Goldbey, E. J., and Jones, T. C. (1949). Cattle feeding trials with derivatives of 2,4,5trichlorophenol. Journal of the American Veterinary Medical Association, 115, 121-123.

Bauer, H., Schulz, K. H., and Spiegelberg, U. (1961). Berufliche Vergiftungen bei der Herstellung von Chlorophenol-Verbindungen. Archiv für Gewerbepathologie und Gewerbehygiene, 18, 538-555.

Cherry, Ralph L. (1972). Washington talks it over. Chemical Marketing Reporter, 16 October, p. 9.

Crow, K. D. (1970). Chloracne. Transactions of St. John's Hospital Dermatological Society, 56, 1350-51.

Farquharson, M. E., Gage, J. C., and Northover, J. (1958). The biological action of chlorophenols. British Journal of Pharmacology, 13, 20-24.

Hofmann, H. T. (1957). Neuere Erfahrungen mit hochtoxischen Chlorkohlenwasserstoffen. Naunyn-Schmiedeberg's Archiv für experimentelle Pathologie und Pharmakologie, 232, 228-230.

, and Neumann, W. (1952). Eine Methode zur tierexperimentellen Prüfung der Hautwirkung chlorierter Naphthaline. Zentralblatt für Arbeitsmedizin und Arbeitsscuhtz, 2, 169-173.

Jensen, N. E., and Walker, A. E. (1972). Chloracne: three cases. Proceedings of the Royal Society of Medicine, 65, 687-688.

Kimmig, J., and Schulz, K. H. (1957). Berufliche Akne (sogenannten Chlorakne) durch chlorierte aromatische zyclische Äther. Dermatologica, 115, 540-546.

McCollister, D. D., Lockwood, D. T., and Rowe, V. K. (1961). Toxicologic information on 2,4,5-trichlorophenol. Toxicology and Applied Pharmacology, 3, 63-70.

Milnes, M. H. (1971). Formation of 2,3,7,8-tetrachlorodibenzodioxin by thermal decomposition of sodium 2,4,5-trichlorophenate. Nature, 232, 395-396.

Quarterly Safety Summary of the Association of British Chemical Manufacturers (1960). Fire and explosionTrichlorophenol (a) Case history No. 620. (b) Supplement to Case No. 620. Vol. 31, p. 22-23.

Schulz, K. H. (1968). Zur Klinic und Ätiologie der Chlorakne. Arbeitsmedizin Socialmedizin Arbeitshygiene, 2, 25-29

Received for publication May 2, 1972.

Accepted for publication December 11, 1972. 